\title{
The Langat River water quality index based on principal component analysis
}

\begin{abstract}
River Water Quality Index (WQI) is calculated using an aggregation function of the six water quality sub-indices variables, together with their relative importance or weights respectively. The formula is used by the Department of Environment to indicate a general status of the rivers in Malaysia. The six elected water quality variables used in the formula are, namely: suspended solids (SS), biochemical oxygen demand (BOD), ammoniacal nitrogen (AN), chemical oxygen demand (COD), dissolved oxygen (DO) and $\mathrm{pH}$. The sub-indices calculations, determined by quality rating curve and their weights, were based on expert opinions. However, the use of sub-indices and the relative importance established in the formula is very subjective in nature and does not consider the inter-relationships among the variables. The relationships of the variables are important due to the nature of multidimensionality and complex characteristics found in river water. Therefore, a well-known multivariate technique, i.e. Principal Component Analysis (PCA) was proposed to recalculate the water quality index specifically in Langat River based on the inter-relationship approach. The application of this approach is not well-studied in river water quality index development studies in Malaysia. Hence, the approach in the study is relevant and important since the first river water quality development took place in 1981. The PCA results showed that the weights obtained indicate the difference in ranking of the relative importance for particular variables compared to the classical approaches used in WQI-DOE. Based on the new weights, the Langat River water quality index was calculated and the comparison between both indexes was also discussed in this paper.
\end{abstract}

Keyword: Langat River; Principal Component Analysis (PCA); Water Quality Index (WQI) 